Proceedings

\title{
When Technology Meets Art: Museum Paths between Real and Virtual ${ }^{+}$
}

\author{
Chiara Panciroli *, Veronica Russo and Anita Macauda \\ Department of Education Sciences “G.M. Bertin”, University of Bologna, Bologna 40126, Italy; \\ veronica.russo6@unibo.it (V.R.); anita.macauda@unibo.it (A.M.) \\ * Correspondence: chiara.panciroli@unibo.it \\ † Presented at the International and Interdisciplinary Conference IMMAGINI? Image and Imagination \\ between Representation, Communication, Education and Psychology, Brixen, Italy, 27-28 November 2017.
}

Published: 16 November 2017

\begin{abstract}
To grasp the elements that make up the museum today it is necessary to have a study approach that identifies the functions of the real museum and its major transformations in relation to the development of technology, with particular reference to digital environments. Starting from these assumptions, this elaboration intends to present the results of observatory research that has taken into consideration a sample of real museums in relation to digital technology. Defined in the common lexicon of museums on the web, those museums that have recently renewed their websites with the aim of getting closer to the their public on digital media are analyzed in the national and International context.
\end{abstract}

Keywords: virtual museum; learning; experience; visitors; involvement

\section{For a Definition of Museum}

To grasp the elements that make up a museum today, which has also taken on the challenge of a virtual nature, a study approach that identifies the functions of a real museum and its principal transformations in relation to technological development, with particular reference to digital environments (sites web) is necessary. So, to define a museum and identify the characterizing elements you need to specify the type of relationship and the level of interaction between the real and virtual dimension of the museum. Recognition of a museum as "a non-profit, permanent institution in the service of society and its development, open to the public, which acquires, conserves, researches, communicates and exhibits the tangible and intangible heritage of humanity and its environment for the purposes of education, study and enjoyment" (International Council of Museums, 2007) remains, without a doubt, one of the most explicit and extensive definitions in the field of museum themes, and leaves ample room for a variety of reflections and insights. Specifically, this elaboration lies within a study area that analyzes the function of museum education in its two-sided real/virtual dimension. It is recognizable that a museum, in order to fulfill its educational mission, needs to go beyond the tangible and intangible building where the collections are contained and open to the public and dialogue with external contexts. In this sense, the public can assume a dual identity:

- $\quad$ partners/collaborators with whom to design and actualize paths;

- $\quad$ users/visitors to whom to propose observation and knowledge itineraries.

A second important aspect in the field of teaching lies in the shift of interest from the function of a museum being only of an exhibition-informational nature to a second being of a constructive-expressive nature. The hypothesis that is prospected is that of a museum as a laboratory with strong educational values, in which the point of view of the subject, his cognitive 
heritage and his interpretations become an integral part of the collections of the museum. We approach this concept of heritage as defined by UNESCO in 2003, in which intangible heritage is understood as the set of "practices, representations, expressions, knowledge, skills-as well as the instruments, objects, artefacts and cultural spaces associated therewith - that communities, groups and, in some cases, individuals recognize as part of their cultural heritage. This intangible cultural heritage, transmitted from generation to generation, is constantly recreated by communities and groups in response to their environment, their interaction with nature and their history, and provides them with a sense of identity and continuity, thus promoting respect for cultural diversity and human creativity" [17] (p. 2). Heritage, in this sense, acquires a procedural nature represented by a group of goods becoming "re-circulated", rebuilding meanings, relocating to spaces for social exchange; or a resource for reflection, questioning, becoming familiar, representing and growing [13] (p. 29).

If the new functions, which maintain a relationship of interdependence with the traditional ones, are determined thanks to the opening of the museum to the social and the new approaches to building knowledge, it is still very necessary they be studied and redefined precisely in relation to educational models capable of grasping the direction of meaning, in a dynamic and continuous recall between theory and educational practice. The reference to pedagogical problematics [2] brings the museum to recognize educational elements of the intellectual and socialization type. Compared to the first, the following levels are recognized:

- cognitive, related to the early literacy of the works contained in the museum;

- metacognitive, through exercise and reflection on possible ways of analyzing cultural heritage;

- creation, in which the subject can reinterpret the work and/or the repertoire and more in general, the collections.

Within socialization, the following are different:

- autonomy, in which the subject demonstrates that he possesses the language and conceptual references in order to continue the visit;

- collaboration, through the sharing of common aims and objectives that allow the participation of a group of visitors within structured museum paths;

- cooperation, in which, on the basis of a planned project, each visitor elaborates, first individually, a specific part of the path and then integrates it a group, creating new museum itineraries.

Considering this educational dimension, the museum represents a "research space" for every visitor who is driven first to discover the "signs" of the messages and, at a later time, to reflect on interpreting and reworking the contents of works, findings, and testimonial memories of historical and recent times.

In addition to enhancing man's "material testimonies", for more than twenty years, museums have been suggesting to preserve and also communicate "intangible assets": This concept of immaterial property to be preserved, protected and communicated leads to the saying the museum emancipates from the original idea of collection towards those intangible assets, defined as those forms of expression that represent in a deep manner the identity of a community and can not be exposed except through the medium with which they are recorded or displayed. It is precisely the term medium and the meaning that educational technology attributes to it in orienting the analysis towards "virtual" museum realities. Finding, in fact, a way to recreate these types of assets, in real museums and outside them, and in particular regarding digital environments, is the priority and perspective of museums. Compared to these new realities, a broad debate has opened up outlining conceptual positions and different attitudes, which highlights precisely the complexity of reflection.

In general, a virtual museum is a "collection of historical, artistic, archaeological, natural and/or scientific digital tools, accessible through multimedia and telematic tools" [3]. The adjective virtual, synonymous to potential, contrasted to the terms "actual, real, effective" finds in the term museum one of the possible contexts to put into effect the objects and collections of the very same museum. With regards to managing content, a virtual museum can digitaline paintings, drawings, diagrams, 
photographs, videos, archaeological sites, architectural and natural environments, findings, scientific instruments that are considered primary goods whether they are representations or not of secondary goods and primary findings. This definition includes locally accessible information systems, such as the multimedia stations all inside traditional museums. Publicly accessible resources through the Internet make it possible to set up spaces called online museums, or more generally web museums, and which find a common denominator in the field of knowledge of an interdisciplinary nature called museum architecture of information and design [8].

A virtual museum is a digital entity that shares some features with the traditional museum, being accessible to an audience, referring to a cultural asset and with educational intent. It aims to complete, better, enhance museum experience through forms of personalization, interaction and enrichment of the contents of the museum. Similarly to the institutional mission of a physical museum, the task of a virtual museum is to be accessible to the public, allowing access to the knowledge connected to the collections and to organize their presentation in a coherent and systematic manner, keeping them for a prolonged period of time. Specifically, the virtual museum can initially be created from real objects, specific themes, or a newly recreated exhibit.

The most common technological features of virtual museums are the following:

- multimedia based media that allows a type of communication that uses different expressive codes (images, texts, sounds);

- being interactive by offering the ability to act, select and actively structure a variety of paths;

- being "connected" or part of a network system that favors access to one or more museum realities;

- $\quad$ in live time.

This system also includes communicative and collaborative services, growing numerous also in museums on the web.

A first category of scholars defines the museum as a real and virtual context for the interpretation of collections of the past, present, and the exploration of the future in which one recognizes the virtual as one of the souls that identifies the museum. This definition is in line with Antinucci's thoughts in which, after "one negative review" to find out exactly what is not a virtual museum, comes to the following definition: "The virtual museum is the all-round communicative projection of the real museum" [1] (p. 115). The "all-around" expression highlights how the virtual museum can use all physical and conceptual means a real museum, without the physical and conceptual limitations of a real museum. The experiments that have come out sometimes appear to be bad copies of real spaces, instead of being exactly the same spaces for deepening unpublished knowledge and original expression for the visitor. A second category considers the telematic network not as a means of the reproduction of reality, but as a tool for the creation of new and original spaces that distribute free collections [9] (pp. 29-30). The achievements in this field are very heterogeneous: some are of particular relevance in terms of consistency with a project and innovation, others in part disappointing, highlighting how the greatest risk is to lose sight of the overall meaning: there is attention to immediate satisfaction that comes from digital and three-dimensional visual effects rather than research of elements of a cognitive and relational nature. This highlights how the virtual nature of the museum also requires clarity on the identity of the museum itself and therefore on the objectives to achieve. The lack of an action plan leads the virtual towards "hybrid" technological solutions. The widespread diffusion of museums on the web leads to the distinction of some typologies:

- real museums on digital: sites that appear as digital transpositions of collections present in the real museums and that directly borrow structure and content;

- virtual museums: sites that collect digital resources of different thematic scopes, disengaged from real museums, accessible only through the use of telematic tools;

- virtual museums with real collections: they are virtually built spaces where the works that are presented are existing and reproduced to be consulted. 
Compared to the first type of museum (real on digital), the museum can find different collocations compared to the real museum:

- anticipatory, that is, beforehand, as preparation for the visit in the real museum;

- consolidator, as an instrument to deepen the knowledge of some aspects of a visit that has already taken place in a real museum;

- dilator, as a training opportunity to rework new content and develop original didactic paths [16] (p. 38).

The virtual museum stands out as an accessible space from where to extract information, not conditioned by physicality and organized in a flexible and shared way. The most widespread function of virtual museums is to accompany traditional museum institutions in carrying out their informative, exhibition and didactic duties, as well as a means of promoting the museum itself. The interactive and hypermedia nature of the web lends itself to providing users with a lot of information, including context, which facilitate the historical understanding of a finding or piece. In this sense, virtual reconstruction technology can be useful in finding the original location of a piece and from there launching several virtual tours with different levels of exploration and depth. Virtual museums, intended as information sites are usually structured over multiple pages and give information on access, location, timetables and on-site services, sometimes accompanied by ticket purchasing services or booking services; information about the history of museum, its development and reference to the staff and services offered by the museum; information about permanent collections, usually made up of thematic catalogs of works and exhibits or logistical catalogs linked to museum maps; information about temporary exhibits, usually having the same characteristics as those related to collections, where notes related to the aims and theoretical principles of the exhibit are added, which sometimes summarize the contents of printed catalogs and/or in digital format.

A second type of museum of a more practical nature has spread with the focus of analyzing and experimenting the knowledge of cultural heritage with different approaches. They are structured in part, following informational museums even though didactic tools are proposed, specifically designed to help understand a piece/finding. It is possible to conduct an in-depth analysis through the links which refer to catalog descriptions, commentary, explanations, details, enlargements and in-depth videos. In this way, the new technology systems make the visit active by placing the works and objects in center of a dynamic personal experience. In fact, traditional audio guides are gradually being felpe by introducing video, interactive apps on smartphones, QR Code systems (Quick Response Coding) and multimedia workstations, such as multi-touch and multi-user digital scanners and walls [11] (pp. 261-264).

\section{Real Museums on Digital: Some Trends on Public Participation on the Web}

The Ministers of Culture at the G7, which took place recently in Italy, during the meeting titled "Culture as an instrument for dialogue among peoples" (2017), recognized "(...) (the) cultural heritage, in all its forms, tangible and intangible, movable and immovable, being an extraordinary link between past, present and future of mankind (...) (as) a driver and a subject of the most advanced technologies and a context for measuring the potentials and opportunities generated by the digital era" (Joint Declaration of the Ministers of Culture of G7, 2017, [6]. From these assumptions, real museums on digital can become a resource to promote access to culture and promote public participation "that is no longer just the real one we find in our museums, but also what is moving online, between websites and social platforms and in research-but at the same time also a giver-of knowledge and suggestions" [7] (p. 306). This reflection is also shared in I Am Culture Symbola and Unioncamere Foundation, which recognizes "the user not just as a consumer of cultural products but increasingly active in the production and delivery of content" [4] (pp.175-176). Therefore, the museum becomes a context "increasingly called to be developed and co-created with the large communities that support it. In this transition, digital innovation provides the infrastructure that multiplies opportunities for exchange, accessibility and participation"(Ibid). For museum institutions, investments resulting from it are therefore characterized by the 
recognition of digital technology as tools primarily related to the everyday life of subjects - and therefore also the main means through which it is possible to approach the interests and needs of different publics (children, young people, families, adults, seniors, tourists, etc.) - and on the other hand, to a participatory design, carried out by professionals with different competences in the field of it, communication, education and museum, aimed at the valorisation of new digital instruments recognized in their potential and used in an innovative way. In reality, this awareness is not always so obvious; there are still few Italian museums working on the improvement of its digital procedures and the perplexities that underlie this phenomenon can also be posed in relation to the need to train professionals that can work "with" and "on" the virtual by acquiring different skills.

Moreover, if digital innovation is spreading in museums, above all, with communication tools such as websites, social networks and newsletters, the Italian heritage reveals a potential of attraction not yet valued. Indeed, as Arnaboldi, Scientific Director of the Observatory of Digital Innovation in Cultural Heritage and Activities in Italy said, "Cultural Institutions are today faced with a double challenge: it is not enough to attract visitors but you need to find a way to communicate your heritage in a new way, bringing it closer to the needs of citizens' knowledge and experience" [18]. "Many institutions have faced the challenge of becoming more efficient and talking to new and old public. Digital innovation, which has led to a radical change in market paradigms in the recent years, could now be a fundamental transformation factor for the cultural sector" (Ibid). Specifically, the Istat ranking "Museums, Archaeological Areas and Monuments in Italy" relating to digital services used in 2015, shows that although more than half of Italian museums have a website (57\%), only $25 \%$ use newsletters to communicate with their audiences, $20 \%$ adopt interactive styles or virtual reconstructions and even lower is the access for visitors to the museum's digital catalog at the virtual visit and use of QR code and proximity services (13-14\%) [5]. However, the usage of social accounts is slowly growing, in fact, if a small percentage of museums are active on the web with blogs and forums (11\%), $41 \%$ of the museums are present on at least one of the main social networks (Facebook, Twitter, Instagram, YouTube, etc.) (Ibid). Recalling also the data on Italian museums provided by Travel Appeal in relation to the use of social networks and visitors' favorite ratings sites - the first in this category being TripAdvisor - the Report I am Culture, points out that content published on social networks has grown by $156.5 \%$, while those posted by visitors increased by $45.5 \%$ [4] (p. 175). Summing up what has been said so far, it seems that the commitment of the Italian museum institutions is moving in the right direction; in fact, as stated in the report I am Culture "an important role in the success of public audience satisfaction is given by the progressive expansion of presence on the network, thanks to the opening of official profiles on different social networks, to the restyling of some websites and making more use of on-line platforms" (Ibid).

At this point, therefore, it is necessary to ask about the objectives defined by the museum institutions to design museums on digital and also the possibilities these environments can offer to visitors. It seems, in fact, that the commitment of the Italian museum institutions, also acknowledged by the writings of many industry scholars in this sector, seems to be more relevant to the communicative value of the museum on digital rather than on its conservative, exhibition function and above all of study, education, and pleasure. From these considerations, it has been therefore decided to carry out observational research that poses the following questions:

1. the real museum on digital, as well as defining itself a space where information can be acquired to also characterize itself as a learning environment [15] (p. 6)?

2. what are the tools and strategies used by the museum on digital to allow visitors to acquire knowledge autonomously and relate to other users?

\section{Research}

This paragraph aims to highlight the results of the observational research it has taken Into consideration a sample of real museums on digital. Specifically, museums selected for research, are the Pinacoteca di Brera [19], the Rijksmuseum of Amsterdam [20] and the Metropolitan Museum of New York [21] chosen by simple random sampling. The search was made using a tool for evaluating museum websites set up by Panciroli during previous research conducted in 2006 on a sample of 
real children's museums on digital-Children's museums - with the intent of "locating those sites that (...) opt for valid content from the pedagogical and didactic points of view, while not omitting the emotional part guaranteed by the graphic aspect and the playful parts of these" [16] (p. 38). The evaluation tool was later used for further research, done in 2010, always coordinated by Panciroli in collaboration with Baldassarri, who individualized the identification of the National and International Museums of Virtual Education [14] (pp. 421-432).

For the present research, the evaluation tool was partly redesigned. Specifically, an item was added to social networks as new communicative tools available to users and another item was dedicated to the identification of accessibility tools. The purpose of the search is not to compare the websites of museums in order to evaluate them positively or negatively but to reflect on the strengths and the criticalities that may favor or otherwise hinder the learning of different audiences. Therefore, this research wants to be the starting point in the fostering of opportunities for dialogue and confrontation with professionals working in the field of museums and working in the direction of improving digital practices.

\subsection{The Tool}

The museum websites' evaluation tool used in the research consists of six areas of interest, each of which is structured according to the specific constructs and corresponding items that allow a systematic observation of digital museum websites.

The six areas of interest are:

1. Identification Area in which the observer expresses general information about the typology of the museum and its characteristics, to the different audiences it is addressed, to the language(s) used.

2. Site Interface Area where the viewer clarifies the usability of the website in terms of usage, the functionality of the internal links (possibility of surfing the site through referrals to the main page and in-depth documents) and external (possibility to connect to other sites and external documents), care of the aesthetic and graphic appearance, the presence of different media languages and accessibility tools, site flexibility in relation to the-presumed-visitors' goals.

3. Content Area where the observer declares whether the content of the site is valid overall and also highlights their "informative, reflective and collaborative" nature. Specifically, if the contents are comprehensible, if they are consistent with the objectives proposed by the museum, the amount of information, services and resources provided, if the content proposed by the site is trusted scientifically and updated continually and, finally, whether the visitor can export them for an autonomous use.

4. Didactics Area where the observer clarifies the teaching model proposed by the museum. In particular, one questions the presence of informative elements, an exhibit space for learning, tools for deepening the content, and laboratory activities that, in some cases, can also be defined as interactive.

5. Process Area where the observer highlights the main educational strategies put in place to support the learning process. In particular, if there is self-learning and/or collaborative learning, if there is support in the learning process for example, help and/or tutoring service, if the user is autonomous in interaction with the environment and, finally, if tracking and/or memorizing of the didactic path is present.

6. Communication Area where the observer declares whether the communicative instruments available on the site are present and functional (email, chat, blogs, forums, social networks, etc.).

The observation tool allows you to identify, for each area of interest, the presence or lack of information, tools, strategies and didactic activities in the museum. There is also space devoted to comments to allow the observer to expose some significant elements they can differentiate according to the context of reference. 
Table 1. Quality Evaluation Form for museum websites, teaching area.

\begin{tabular}{|c|c|c|c|c|c|}
\hline $\begin{array}{c}\text { Areas of } \\
\text { Investigation }\end{array}$ & $\begin{array}{l}\text { Definition of } \\
\text { Construct }\end{array}$ & Constructs & Yes & No & Comments \\
\hline \multirow{5}{*}{$\begin{array}{l}\text { DIDACTIC } \\
\text { AREA }\end{array}$} & \multirow{5}{*}{$\begin{array}{l}\text { Didactic model } \\
\text { proposed by the } \\
\text { museum }\end{array}$} & Presence of information elements & & & \\
\hline & & Presence of an exhibit space for learning & & & \\
\hline & & Presence of tools for deepening content & & & \\
\hline & & $\begin{array}{c}\text { Presence of laboratory activities for } \\
\text { deepening content }\end{array}$ & & & \\
\hline & & Presence of interactive workshops & & & \\
\hline
\end{tabular}

\subsection{The Results}

This section explains the main results of the analysis of the three museums on digital: Brera Art Gallery, the Rijksmuseum of Amsterdam and the Metropolitan Museum of New York. The main reflections that emerged from the analysis relate, in particular, to the following dimensions: the public, the interface of the site, exhibit set-ups, media languages, personal space and communication tools.

\subsubsection{The Public}

The audience targeted by the three digital museums is predominantly for adults, even though the Metropolitan Museum has dedicated a section, called Metkids, which allows children to get to know the museum in a more fun and interactive way giving them the chance to play, watch videos and participate in a specially reserved blog. The Rijksmuseum, as well as the Metropolitan Museum, places special emphasis on professionals, scholars and artisans in the world of museums and arts. In this regard, these museums devote a specific digital section to scientific research; the visitors can get to know the mission of the museum, the professionals that work within them, research activities and training - such as symposiums, Master's or summer school-and also have the opportunity to access job offers, scholarships and internships. In addition, the Metropolitan Museum also addresses particular attention to school teachers of every order and degree; inside the digital museum, in fact, there is a section where classes are offered to help integrate the learning of works of art into the classroom. For each lesson there are goals, didactic activities, timetables, spaces, materials and a reference bibliography.

\subsubsection{Site Interface}

Looking at the interface of the site, from an aesthetic and graphic point of view there is particular care in all three museums with similar design in the digital architecture: a menu that develops horizontally or vertically, with disappearing subcategories and a high definition image gallery that runs automatically and that, linkable, refer to pages inside the site where there is news about exhibitions, retrospectives and scheduled events. In the homepage there is also a free search mask and login for user registration while a site map which may be useful in preventing the "less experienced" visitor from appearing disoriented in navigation is completely absent in all three museums. Specifically, by analyzing the different websites it is noted that the Rijksmuseum, less rich in content, differs from the Brera Art Gallery and the Metropolitan Museum by using all of the main page space for a purely informative purpose instead. In fact, ticket buying links, calendars with events, blog links, links to the main social network and more are present. Pages are updated at regular intervals, allowing the visitor to be aware of the latest events in the program-exhibitions, multimedia tours, games (such as family games organized at Rijksmuseum) etc. - and sharing the information on social networks. In addition, the three museums allow the visitor to be aware of the main digital didactic activities that take place at the Royal Museum, depending on the type of public. In particular, the Rijksmuseum, in addition to describing the various activities, adds gallery of images related to the different didactic paths created by the museum with the possibility, for different publics, to book them and even buy entry tickets. Also, the visitor to the Brera Art Gallery 
can download the teaching material for the digital museum, useful both before and during the visit to the real museum. In addition, the Metropolitan Museum user who has children, can find out about access to the library of the real museum containing books suitable for all ages, to use the audioguide specially designed for children and families during the visit and also to download for free the map of the real museum dedicated to them, all through digital media. With a large presence of internal and external connections, the Metropolitan Museum, the Rijksmuseum and the Brera Art Gallery allow visitors to surf within the digital museum but also to connect to other internet sites and access documents for more information. For example, within the Rijksmuseum the visitor can access the Rijksmuseum Research Library, an online resource catalog published in the museum library and can also view, through internal and external links, recent scientific publications on the museum and museum exhibits and have the opportunity to read contributions, to get to know the authors, and to consult the bibliographical references.

\subsubsection{Exhibits}

Analyzing the Content Area, the Brera Art Gallery, the Rijksmuseum and the Metropolitan Museum use a digital document archiving system to exhibit artwork inside special galleries. This metadata system, by means of a standard and interoperable language, associates with each piece of art with descriptive information (title, author, year, description, etc.) that allows the visitor to get to know the works of art by studying their characteristics, to find additional information thanks to documents of in-depth and bibliographical references and to consult, including through links directed to other online resources, additional images that are closely related to each other because of the same author, year, subject or subject. Self-learning can therefore take place on digital through the enjoyment of works of art that, side by side with texts, descriptions and in-depth documents, allow the visitor to acquire new knowledge and/or deepen particular content considered to be particularly significant. Visitors also have the opportunity to see the works in high definition, to enlarge them in order to capture every detail, to download them, print them, and share them on social networks. The visitor can also use a research mask to find works-even those not physically present in the museum-and other in-depth content such as texts, documents and books that are structured according to records or fields such as: historical date-time, artist, material, technique, museum map, thematic set-up (fashion, sculptures, paintings, etc.). Specifically, it is interesting that the Brera Art Gallery visitor has the possibility to consult the description sheet to se if the works of art are "on display" or "not on display". In this case, the visitor may also observe works of art not physically present in the real museum. With regards to exhibits and/or retrospectives under construction, the Metropolitan Museum allows you to also see the digital works in the real museum, to listen to the audio related to every work, to view the publications, to understand the placement of the "room" in which the piece is contained inside the real museum from the map, to look at other pieces from the same collection so as to "suggest" any conceptual ties to be deepened by the visitor. The Metropolitan Museum also gives you the chance to see some artwork in 3D and access to the "Timeline of Art History" that allows to interrelate "essays and works of art with chronologies, telling the story of art and global culture through the museum's collection". 


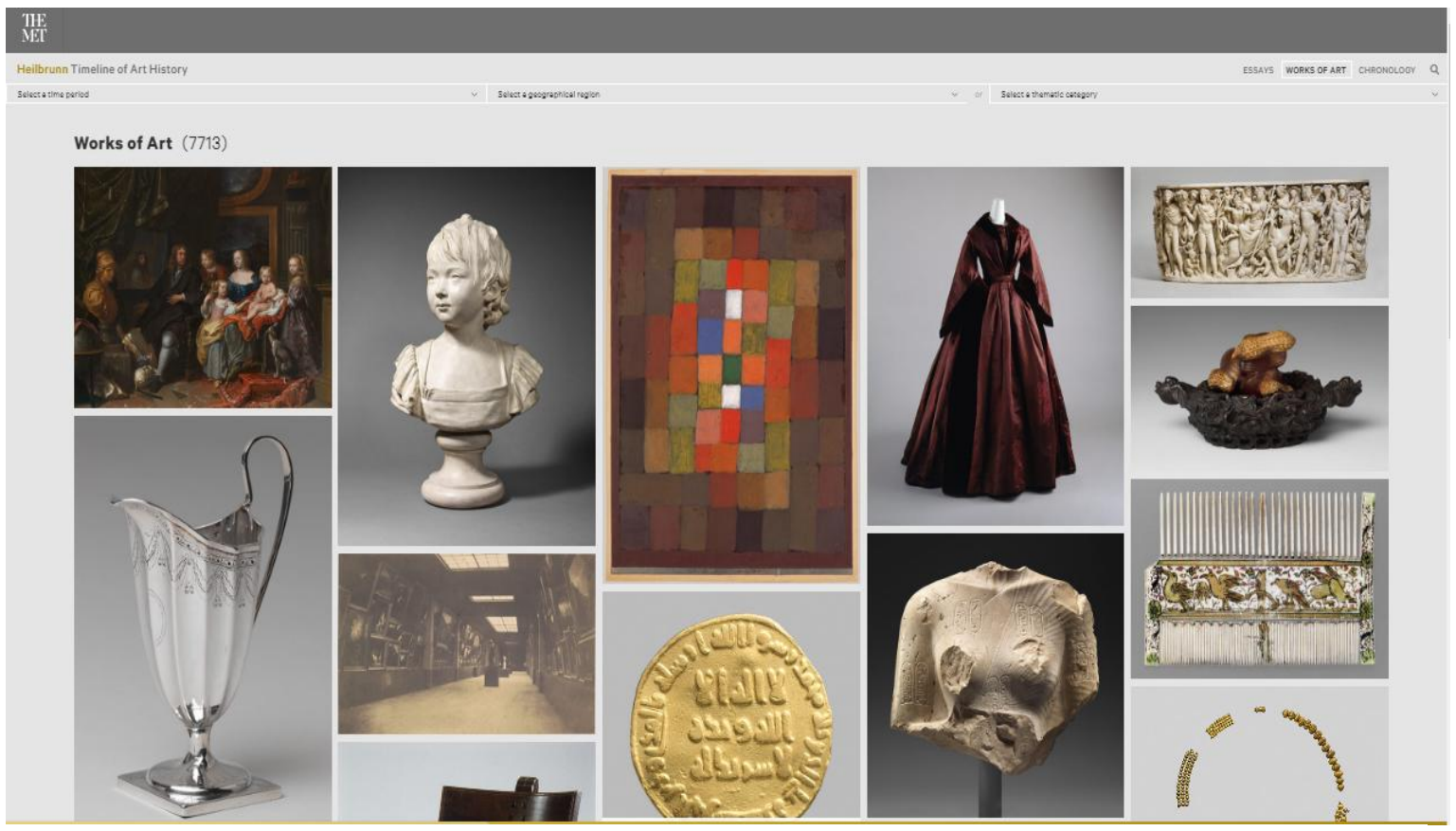

Figure 1. Timeline of Art History, Metropolitan Museum of New York, website.

As for the textual content used to metadate the works of art or to create sections of in-depth study in all three museums the identity of the authors who created them can not be traced. Inside the Metropolitan Museum however, digital bibliographies valid from a scientific point of view are present: Visitors inside the galleries can, in fact, fully refer to the bibliographies of works or exhibits and, through internal and external links, also have access to the online catalog with museum publications which, in some cases, are open access. Brera Art Gallery also gives the possibility to freely access in-depth documents.

\subsubsection{Media Languages}

Emerging from the analysis therefore, the Metropolitan Museum, the Rijksmuseum and the Brera Art Gallery present different media languages: high-definition image galleries, photographs, audio and video. For example, regarding the video, in the "Brera Media" section of the Brera Art Gallery, the visitor can watch videos featuring exhibits as well as lessons and stories about paintings on display.

The Metropolitan Museum also collects videos-about 1181 at present-and visitors can select the main channels to follow depending on their interests. It is also possible to watch videos of the exhibits and read the in-depth content on digital at the Rijksmuseum. At the Metropolitan Museum, in the Metkids section, children can play interactive games with "the time machine" to discover the works of art in the museum; It is also possible to listen to the story of the work and play games, together with their peers. 


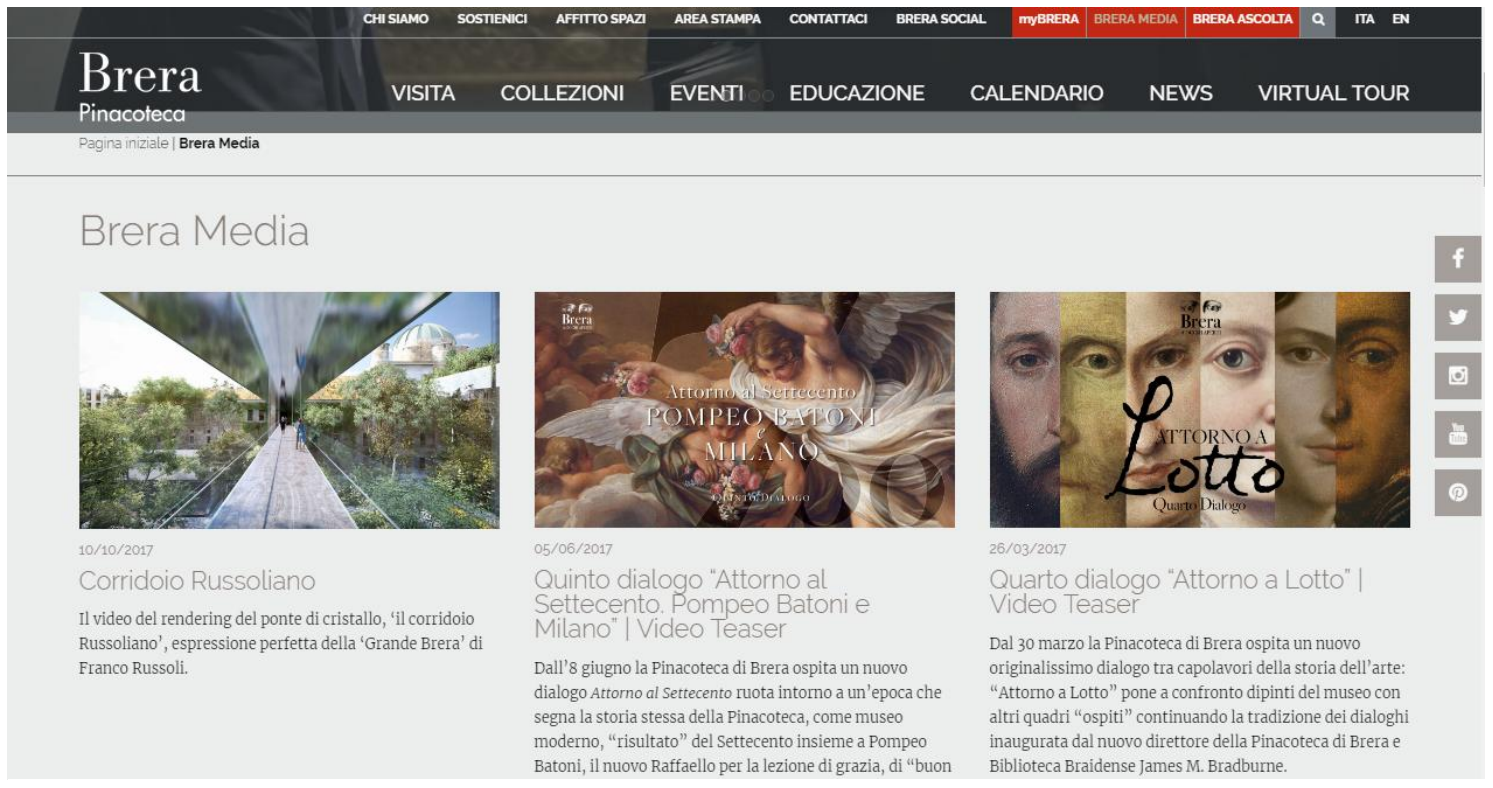

Figure 2. Brera Media, Brera Art Gallerv of Milan, website.

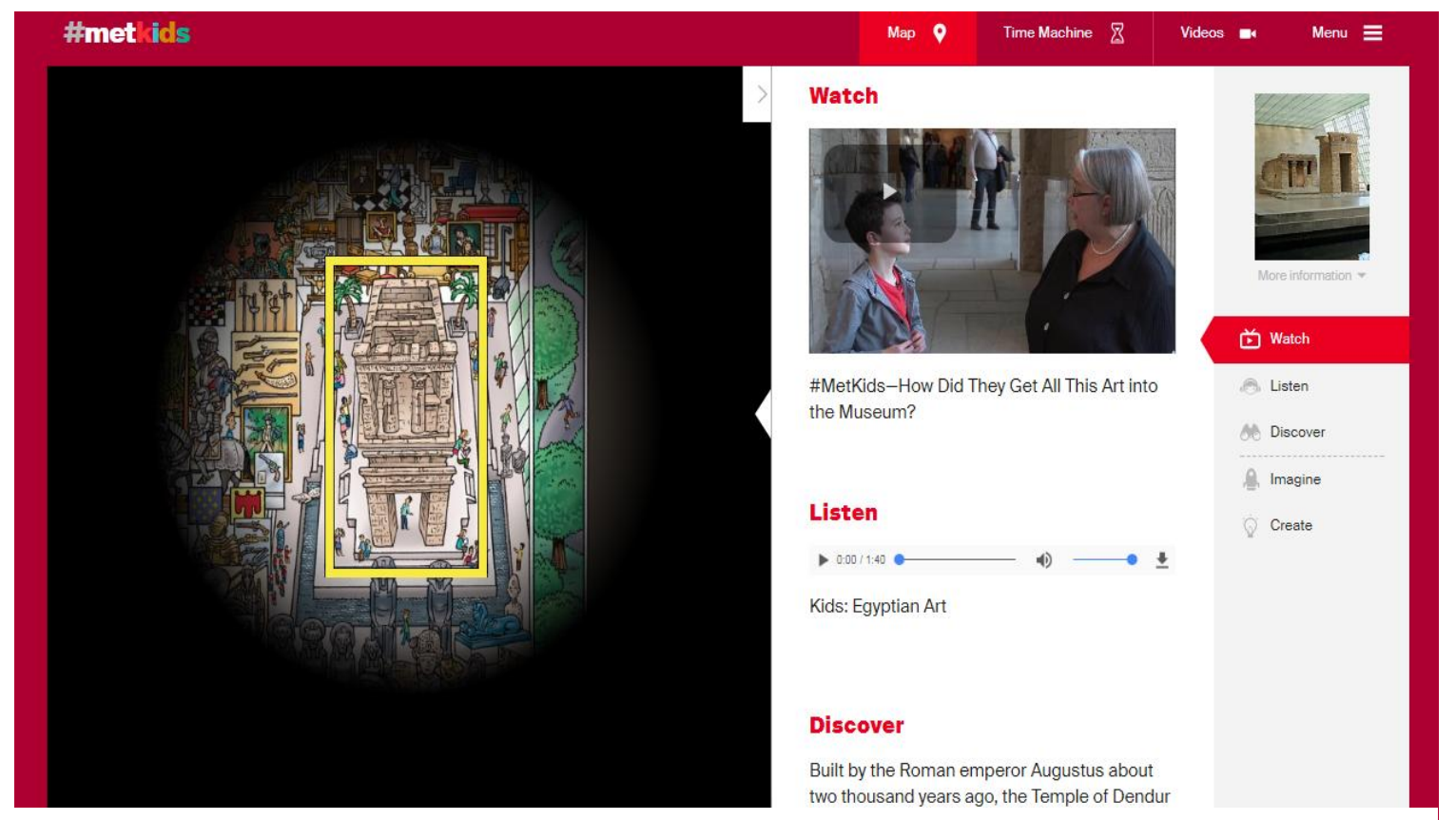

Figure 3. Metkids section, Metropolitan Museum of New York, website.

Despite some museums-like the just mentioned Metropolitan Museum -use audio tools to recount their works of art and make them accessible to different types of art users, there seems to be no explicit reference to the presence of accessibility tools, except for the Brera Art Gallery that declares that the site was designed according to the standards for creating web content accessible to everyone.

\subsubsection{Personal Space}

Of the three museums analyzed, only the Rijksmuseum gives visitors the chance to have a personal space in which to carry out activities. In fact, in the Brera Art Gallery this space is totally absent while inside the Metropolitan Museum while being present-it requires registration and 
page access-resulted non-functioning. The Rijksmuseum has built a personal space called "Rijksstudio" that allows the visitor to save their favorite artwork selected, starting with the vision of the works inside the gallery of the digital museum. Specifically, the visitor can choose whether to save the works or select the details that they think are particularly interesting and to also create virtual exhibits. In this space, therefore, the tracking and storage of a visitor's path who also has the possibility to return to his personal page and to see his creations over time is present. These are also visible to all users within the digital museum and can be shared on social networks. The visitor can search for pieces in the "Search in Rijksstudio" section by looking at the collections created by other users in their Rijksstudios.
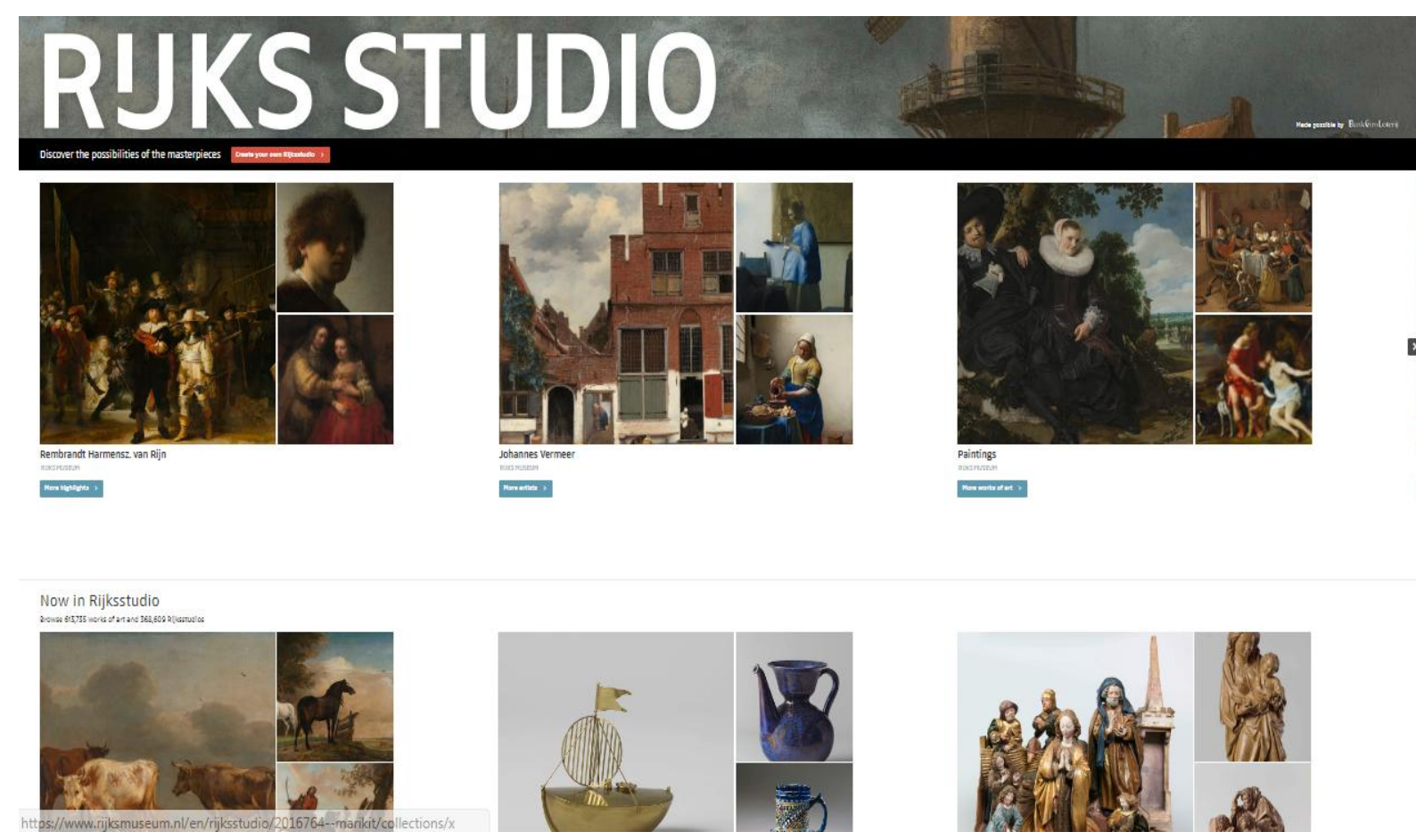

Figure 4. Rijksstudio, Rijksmuseum of Amsterdam, website.

The visitor is therefore involved in the learning process as they access the content autonomously and acquire knowledge by interpreting, organizing and structuring information in order to manage it independently. The visitor is also stimulated to reinvent his knowledge in an original way by setting up paths in order to revisit his learnings. We can therefore say that within this space a workshop activity that can address audiences of all ages is present. As for collaborative learning, though there is sharing between users regarding the exhibits created in their own Rijksstudios, there is no real participation of visitors who, in fact, express their appreciation only by using the "like" button on the social network; this strong aspect from a communicative point of view appears rather weak on the didactic side.

\subsubsection{Communication Instruments}

To communicate with their digital visitors, the Brera Art Gallery and the Rijksmuseum use at least two languages. Moreover, both museums offer the main information in five or six languages, in addition to their own, an aspect that is not found inside the Metropolitan Museum that uses only their native English. In addition, the Metropolitan Museum, the Brera Art Gallery and the Rijksmuseum use the email tool, allowing the visitor to contact the facility if needed. In particular, the Metropolitan Museum indicates multiple e-mail addresses depending on user requirements - for example visits, career opportunities etc. - and, as is also the case within the Rijksmuseum, an additional email address for any questions about the issues that may be encountered while browsing 
the web site. Moreover, in all three museums there is no evidence of support for the learning process with, for example, tutors or help. The Rijksmuseum, for example, provides a FAQ which is not dedicated to the site but to information about visits and activities at the museum. Inside the Brera Art Gallery a specific e-mail address for surfing the web site cannot be found but only the e-mail of the structure is found.

The service dedicated to the newsletter, featured in the three museums, allows visitors to stay updated on collections, exhibits, events and more. The possibility the Rijksmuseum offers visitors to subscribe to two different newsletters: "family newsletter" and "academic newsletter" is particularly interesting. Neither the chat tool nor the forum tool can be found in the three museums. However, the Metropolitan Museum has created a blog section. By way of example, MetKids is mentioned as a blog created for, with and from kids to find out what to learn from young museum visitors across the world and also the Teen Blog, a space for teenagers to talk about art and related topics at the Museum. Communicating with museum audiences, whether real or potential, also occurs through social networks; all three museums have chosen more than one: Facebook, Twitter, Instagram, Pinterest, in addition to using the Youtube platform. In particular, the Brera Art Gallery has created a page on the inside of the digital museum, called "Brera Social", where last posts published on the main social networks can be seen.

\section{Conclusions}

To conclude, we can state that observational research has highlighted some aspects that deserve to be looked at more in depth.

Firstly, all three museums give special attention to the content of information and communication, especially in relation to the main services offered by museums. The visitor can always be up-to-date on planned events, on proposed didactic activities and has access to online ticket purchases. The investment that the three museums are carrying out regarding the realization of digital exhibit paths involving the metadata of works of art and, more generally, the construction of virtual outfits is also very significant. Specifically, the valorization of works that find a place within digital paths that act as an interface with the real museum where objects are physically placed is noted in all three museums. With regards to this, there is also the desire by digital museums to regive life to objects that risk being confined to closed and dusty deposits, and which can instead be used by all subjects within "democratic" learning spaces and that can "ensure everyone free access to spaces, information, and communication, to the collections, in the full development of the social role" [10] (p. 17).

Secondly, it is noted that the real museums on digital, as well as being characterized as information spaces, can integrate with real museums by favoring experiences of fruition and alternative learning but, from an educational point of view, equally relevant. In fact, "the experience inside a virtual museum does not replace the real one but rather expands the possibilities of relationships and interaction with other contexts, within which to create new learning experience" ([12], p. 408). In this sense, self-learning paths should allow the visitor not only to know the works of art within the exhibit set-ups, but to also personalize the path according to their own interests and to "motivate reflection, interpretation and research, so that the visitor shares with the museum and with other visitors their views, becoming an active contributor and creator of new paths" [12] (p. 409). However, the analysis carried out on the three museums shows a shortage of personal spaces dedicated to users; one museum out of three actually makes that space usable but when this happens, visitors are actively involved in the learning process. The visitor accesses content independently, deepens, uses high-definition works by capturing interesting details and reinterpreting the knowledge in an original way, thanks also to the visitor's specially created virtual exhibits.

Thirdly, the is sharing between users still weak: in fact, if the main communicative tool present in all three museums is social networks, these certainly do not favor collaborative learning on the net. This aspect therefore raises questions about the choice of tools to be favoured to design, from a point of view not only communicative but also didactic, virtual museum environments. 
Author Contributions: Chiara Panciroli and Anita Macauda (paragraphs 1- 2); Veronica Russo (paragrah 3)

Conflicts of Interest: 'The authors declare no conflicts of interest'.

\section{References}

1. Antinucci, F. Musei Virtuali. Come Non Fare Innovazione Tecnologica; Roma-Bari: Laterza, Italy, 2007; ISBN 9788842082866 .

2. Bertin, G.M. Educazione Alla Ragione; Armando Editore: Roma, Italy, 1968.

3. Casalino, A. Musei Più Bambini: L'occhio ha Saltato il Muro? Pendragon: Bologna, Italy, 2002; ISBN 88-8342-116-7.

4. Fondazione Symbola \& Unioncamere. Rapporto Io Sono Cultura, L'Italia Della Qualità e Della Bellezza Sfida la Crisi, Io Sono Cultura; Quaderni di Symbola: 2017; Available online: http://www.symbola.net/assets/files/IoSonoCultura_2017_DEF_1498646352.pdf（accessedｏn 12 September 2017).

5. Istat. Musei, $i$ Monumenti e le Aree Archeologiche in Italia, 2016. Available online: https://www.istat.it/it/files/2016/12/Report-Musei.pdf?title=Musei+e+monumenti+in+Italia+-+19\%2Fdic\%2 F2016+-\%20+Testo+integrale.pdf (accessed on 12 September 2017).

6. Joint Declaration of the Ministers of Culture of G7, Meeting "Culture as an Instrument for Dialogue among Peoples", Florence, Italy, 30-31 March 2017. Available online: http://www.beniculturali.it/mibac/multimedia/MiBAC/documents/1490881204940_DECLARATION-Dich iarazione.pdf (accessed on 13 September 2017).

7. Mandarano, N. Introduzione, Parte IV, Comunicare il useo come?. In Comunicare il Museo Oggi. Dalle Scelte Museologiche al Digitale; Branchesi, L., Curzi, V., Mandarano, N., Eds.; Skira: Milano, Italy, 2016, ISBN 9788857233901.

8. Mandelli, E. Architettura Dell'informazione e Design Museale; Tafter Journal. Esperienze e Strumenti per Cultura $\quad$ e $\quad 2011 . \quad$ Territorio, Available online: http://www.tafterjournal.it/2011/07/01/architettura-dell\%E2\%80\%99informazione- e-design-museale/ (accessed on 13 September 2017).

9. Marani, P.C.; Pavoni, R. Musei. Trasformazioni di Un'istituzione Dall'età Moderna al Contemporaneo; Marsilio: Venezia, Italy, 2016, ISBN 9788831790147.

10. Scarpati, D. (Ed.) Glossario Dell'accessibilità Museale; ICOM Italia: Milano, Italy, 2016. Available oonline: http://www.icom-italia.org/images/glossario\%20accessibilit\%20museale.pdf (accessed on 14 September 2017).

11. Panciroli, C., Tecnologie digitali e realtà aumentata per nuove modalità di fruizione museale. In Le Professionalità Educative tra Scuola e Musei. Esperienze e Metodi Nell'arte; Guerini Editore: Milano, Italy, 2016; ISBN 9788881074006.

12. Panciroli, C.; Russo, V. I musei come luoghi per l'educazione permanente. In L'educazione Permanente a Partire Dalle Prime età Della Vita; FrancoAngeli: Milano, Italy, 2016; ISBN 9788891734198.

13. Panciroli, C. Le valenze formative del bene culturale tra scuola e musei. In Formare al Patrimonio Nella Scuola e nei Musei; QuiEdit: Verona, Italy, 2015; ISBN 9788864643489.

14. Panciroli, C. II modello di Museo Virtuale dell'Educazione dell'Università di Bologna, Ricerche di Pedagogia e Didattica. J. Theor. Res. Educ. 2010, 5. Available online: https://rpd.unibo.it/article/viewFile/1916/1309 (accessed on 14 September 2017).

15. Panciroli, C. E-learning e learning-e. Riflessioni sulla formazione, 2008, Ricerche di Pedagogia e Didattica. J. Theor. Res. Educ. 2008, 3, 1000-1028. Available online: https://rpd.unibo.it/article/viewFile/1539/912 (accessed on ,16 September 2017).

16. Panciroli, C. I Musei Virtuali per L'educazione; Infanzia, Airplane; Ozzano Dell'Emilia: Bologna, Italy, 2006; Volume 1-2. ISBN 8883723236.

17. UNESCO. Convention for the Safeguarding of the Intangible Cultural Heritage; UNESCO: Paris, France, 2003, p.2. Available online: http://unesdoc.unesco.org/images/0013/001325/132540e.pdf (accessed on 10 September 2017).

18. https://www.osservatori.net/it_it/osservatori/executive-briefing/il-52-dei-musei-italiani-e-social-ma-i-serv izi-digitali-per-la-fruizione-delle-opere-sono-limitati (accessed on 15 September 2017).

19. http://pinacotecabrera.org/ (accessed on 18 September 2017). 
20. https://www.rijksmuseum.nl (accessed on 18 September 2017).

21. http://www.metmuseum.org/ (accessed on 18 September 2017).

(C) 2017 by the author. Licensee MDPI, Basel, Switzerland. This article is an open access article distributed under the terms and conditions of the Creative Commons Attribution (CC BY) license (http://creativecommons.org/licenses/by/4.0/). 